\title{
A Research on Working Conditions and Work Morale of Domestic and Foreign Workers in South Korea
}

\author{
Jin-Ho Kim (kjh@kongju.ac.kr) ${ }^{1}$, Chung-Won Lee(smartwony@naver.com)1, \\ Hee-Chang Jung (junghc@yu.ac.kr)², \\ ${ }^{1}$ Kongju National University. Department of Industrial and System engineering. \\ ${ }^{2}$ YeungnamUniversity Medical
}

\begin{abstract}
This study aimed to analyze working conditions and work morale of domestic and foreign workers in South Korea. The study used the primitive data of the fourth Korean Working Conditions Survey (KWCS) conducted by the Occupational Safety and Health Research Institute (OSHRI) in 2014. The KWCS is a survey to identify an overall work environment including work type, employment type, occupation type, business type, exposure to risk factors and job security of the workers over fifteen years of age across the country by benchmarking the Europe Work Condition Survey (EWCS) and the U.K. Labour Force Survey (LFS). The survey data reflects the characteristics of 50,000 workers over fifteen years of age living in the Republic of Korea. This study used the factors of occupation type, work attitude and work-related autonomy to analyze working conditions, and used the psychological factors including competence and stress level of work to analyze work morale. It is expected to enhance understanding of poor work conditions of foreign workers in South Korea and their psychological problems through this study.
\end{abstract}

Keywords: Working condition, Work morale, Foreign workers, ESK-JES Joint Session

\section{Introduction}

According to the Foreign Worker Employment Survey by Statistics Korea, the number of foreign workers in South Korea is annually increasing to 1.055 million people in 2016 from 0.986 million people in 2015 and 0.896 million in 2014. The work experiences of foreign workers in South Korea can have a huge influence on the images or confidence of South Korea in this era of globalization. Nevertheless, the studies on their working conditions or work morale were not paid attention and there have been few studies on the issue. Therefore, this study aimed to identify the current status of the working conditions and work morale of foreign workers in South Korea and further improve their working conditions.

\section{Method}

The study analyzed the results of The Forth Korean Working Condition Survey (2014). The Forth Korean
Working Condition Survey (2014) is a data that reflected the characteristics of 50,000 employees aged over 15 across the country.

\section{Results}

\subsection{Major Types of Occupation}

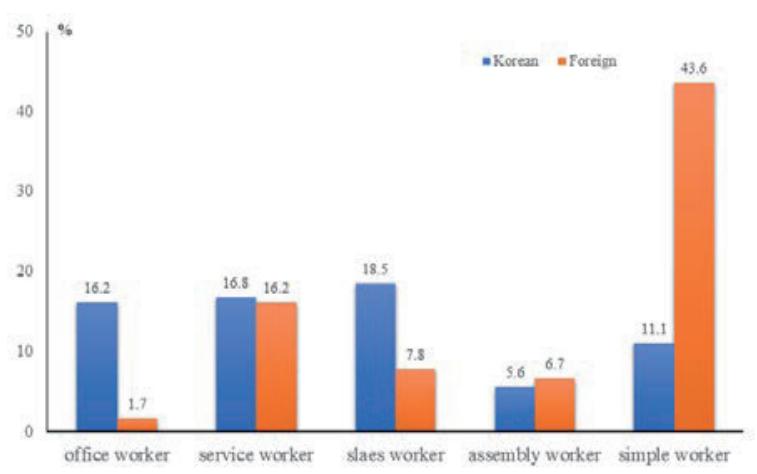

Figure 1. Comparison of Major Types of Occupation between

Korean and Foreign Workers 
In comparison of major types of occupation between domestic and foreign workers, a relatively high proportion of Korean workers were office and sales workers and a significantly high rate of foreign workers were simple workers.

\subsection{Difference in Working Conditions}

The questionnaire items to measure the working conditions are on the Likert scale of 1-7 (1 point: all working hours -7 point: never been exposed) and the lower point means a higher exposure.

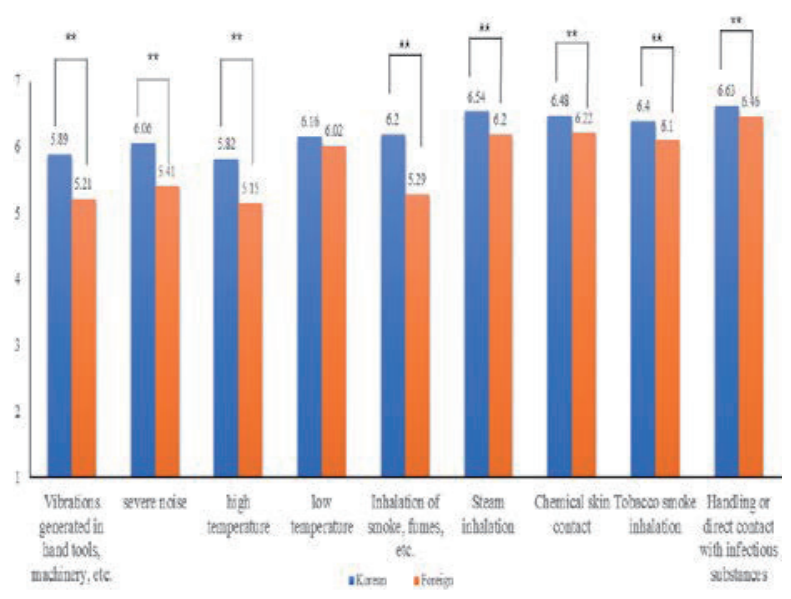

Figure 2. Verified Results of Difference in Working Conditions between Korean and Foreign Workers

The t-test on the work conditions of domestic and foreign workers found significant differences in all factors except for low temperature at a confidence level of $95 \%$. Overall, the working conditions of foreign workers were poorer than domestic workers and especially the foreign workers were highly exposed to inhalation of smoke or fume (welding fume or exhaust emissions).

\subsection{Comparison of Work Morale}

The questionnaire items to measure the work morale were on the Likert scale of 1-5 (1 point: always -5 point: not at all).

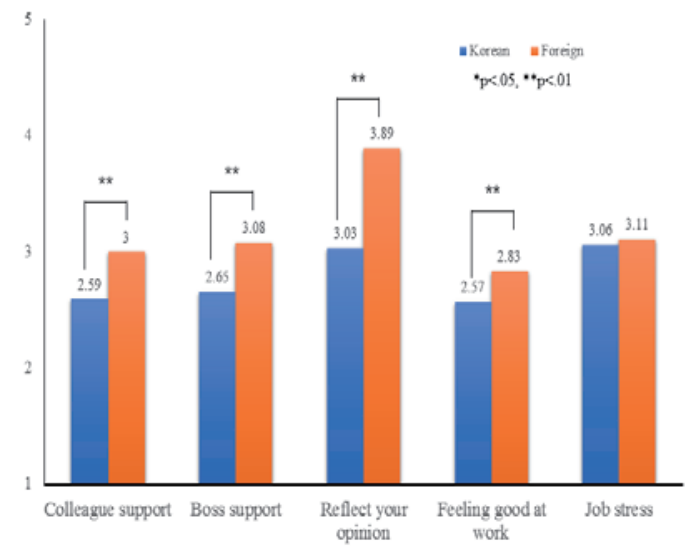

Figure 3. Verified Results of Difference in Work Morale between Korean and Foreign Workers

According to the t-test results on the working conditions of domestic and foreign workers, there were significant differences in all factors except for job stress at a confidence level of $95 \%$. Overall, it was identified that foreign workers were less supported by colleagues or bosses and they felt a relatively low sense of achievement at work that their opinions were adopted or they did good works. However, there was no statistically significant difference in job stress between domestic and foreign workers.

\section{Conclusion}

It was identified that foreign workers were working under poorer conditions than domestic workers and had a very low work morale. It is considered necessary for companies to make various efforts to improve the working conditions and work morale of foreign workers in order to adapt to the realities of the increasing number of foreign workers.

\section{References}

KOSIS.” Economically active population survey”, 2017

The Forth Korean Working Conditions Survey., Occupational Safety and Health Research Institute, 2014

Yun, K. S., "A Comparative Analysis of Korea and Japan on Industrial Structures and Linkages in the Service Industry", Asia Studies, 18(3), 105-124, 2015. 